\title{
Papers
}

\section{Accuracy of cervicovaginal fetal fibronectin test in predicting risk of spontaneous preterm birth: systematic review}

\author{
Honest Honest, Lucas M Bachmann, Janesh K Gupta, Jos Kleijnen, Khalid S Khan
}

\begin{abstract}
Objective To determine the accuracy with which a cervicovaginal fetal fibronectin test predicts spontaneous preterm birth in women with or without symptoms of preterm labour.

Design Systematic quantitative review of studies of test accuracy.

Data sources Medline, Embase, PASCAL, Biosis, Cochrane Library, Medion, National Research Register, SCISEARCH, conference papers, manual searching of bibliographies of known primary and review articles, and contact with experts and manufacturer.

Study selection Two reviewers independently selected and extracted data on study characteristics, quality, and accuracy.

Data extraction Accuracy data were used to form $2 \times 2$ contingency tables with spontaneous preterm birth before 34 and 37 weeks' gestation and birth within 7-10 days of testing (for symptomatic pregnant women) as reference standards. Data were pooled to produce summary receiver operating characteristic curves and summary likelihood ratios for positive and negative test results.

Data synthesis 64 primary articles were identified, consisting of 28 studies in asymptomatic women and 40 in symptomatic women, with a total of 26876 women. Among asymptomatic women the best summary likelihood ratio for positive results was 4.01 (95\% confidence interval 2.93 to 5.49) for predicting birth before 34 weeks' gestation, with corresponding summary likelihood ratio for negative results of 0.78 (0.72 to 0.84 ). Among symptomatic women the best summary likelihood ratio for positive results was 5.42 (4.36 to 6.74) for predicting birth within 7-10 days of testing, with corresponding ratio for negative results of 0.25 (0.20 to 0.31 ).
\end{abstract}

Conclusion Cervicovaginal fetal fibronectin test is most accurate in predicting spontaneous preterm birth within 7-10 days of testing among women with symptoms of threatened preterm birth before advanced cervical dilatation.

\section{Introduction}

Spontaneous preterm birth occurs in $7-11 \%$ of pregnancies before 37 weeks' gestation ${ }^{12}$ and in $3-4 \%$ of pregnancies before 34 weeks' gestation. ${ }^{3}$ Most neonatal deaths of normally formed infants occur when they are born before 34 weeks' gestation. Many of the surviving preterm infants, especially those from the earlier gestations, suffer serious morbidity such as bronchopulmonary dysplasia, intraventricular haemorrhage, retrolental fibroplasia, neurodevelopmental problems, and cognitive difficulties. ${ }^{45}$ Advances in perinatal health care have not altered the incidence of spontaneous preterm birth, but there is effective management to reduce the associated complications. For example, the landmark Cochrane review showed that antenatal steroids significantly reduced morbidity and mortality. ${ }^{6}$ Timely institution of such treatment in clinical practice depends on accurate prediction of spontaneous preterm birth.

Many tests have been purported to predict spontaneous preterm birth including cervicovaginal fetal fibronectin testing. Fetal fibronectin is a glycoprotein found in amniotic fluid, placental tissue, and the extracellular substance of the decidua basalis next to the placental intervillous space. It is thought to be released through mechanical or inflammatory mediated damage to the membranes or placenta before birth. ${ }^{7}$ Swabs can be taken from the ectocervix or posterior vaginal fornix, and an enzyme linked immunosorbent assay (ELISA) containing FDC-6 monoclonal antibody can be used to detect fetal fibronectin. ${ }^{7}$ The results may indicate the likelihood of spontaneous preterm birth. ${ }^{8}$ In clinical use, however, factors such as contamination of the sample with maternal blood, ${ }^{9}$ sampling within 24 hours after intercourse, ${ }^{10}$ and pre-eclampsia ${ }^{11}$ may reduce the accuracy of the test and give false positive results.

If the test could be used to identify those women who, though asymptomatic, may be at high risk antenatal care may be optimised (for example, by instituting closer antenatal surveillance) with view to maintaining the pregnancy past 34 weeks' gestation, which is now an established milestone in perinatal outcome. ${ }^{45}$ On the other hand, if the test could predict imminent birth among women with symptoms of threatened spontaneous preterm birth but before advance cervical dilatation then antenatal steroids, tocolytics, and in utero transfer (to optimise neonatal care) may be used accordingly. Antenatal steroids are

\begin{tabular}{l} 
Editorial \\
by Colombo \\
\hline \\
Academic \\
Department of \\
Obstetrics and \\
Gynaecology, \\
Birmingham \\
Women's Hospital, \\
Birmingham \\
B15 2TG \\
Honest Honest \\
research fellow \\
Janesh K Gupta \\
senior lecturer \\
Khalid S Khan \\
consultant \\
Horten Centre, \\
University of \\
Zurich, \\
Bolleystrasse 40, \\
CH-8091,Zurich, \\
Switzerland \\
Lucas M Bachmann \\
research fellow \\
NHS Centre for \\
Reviews and \\
Dissemination, \\
University of York, \\
YorkYO10 5DD \\
Jos Kleijnen \\
professor \\
Correspondence to: \\
H Honest \\
h.honest@ \\
bham.ac.uk \\
bmj.com 2002;325:301
\end{tabular}

bmj.com 2002;325:301 
most effective in the two to seven days after they are given, ${ }^{6}$ and tocolytics can delay birth for at least two days. Therefore, among symptomatic women we are mostly interested in predicting the likelihood of spontaneous preterm birth occurring within 7-10 days after the test because this knowledge is likely to influence subsequent management.

Many primary studies claim that the cervicovaginal fetal fibronectin test can accurately predict spontaneous preterm birth in a clinical setting. However, these studies have not generally had enough participants to provide precise estimates of accuracy. In addition, existing systematic reviews have been restricted to a few databases, ${ }^{12-15}$ their study selection has often been limited by language, ${ }^{12} 1315$ and often they have not assessed study quality. ${ }^{12-14}$ These factors are known to introduce potential for bias. ${ }^{16}$ We conducted a comprehensive and rigorous systematic review to obtain reliable estimates of accuracy. We defined asymptomatic women as those without uterine tightenings or contractions and symptomatic women as those with uterine tightenings or contractions and cervical dilatation of $<2-3 \mathrm{~cm}$.

\section{Methods}

We used a prospective protocol with widely recommended methods. ${ }^{17} 18$

\section{Identification of studies}

Our electronic searches targeted all diagnostic procedures among studies on prediction of spontaneous preterm birth. We searched general bibliographic databases: Medline (1966-2000), Embase (1980-2000), PASCAL (1973-2001), and BIOSIS (1969-2001). We also searched specialist computer databases: the Cochrane Library (2000:4), MEDION (1974-2000) (a database of diagnostic test reviews set up by Dutch and Belgian researchers), National Research Register (2000:4), SCISEARCH (1974-2001), and conference papers (1973-2000). Our electronic search strategy is described in detail elsewhere. ${ }^{19}$ We contacted individual experts and the manufacturer of fetal fibronectin test to uncover grey literature. We also checked reference lists of known reviews and primary articles to identify cited articles not captured by electronic searches.

\section{Study selection and data extraction procedures}

Our selection criteria were studies in asymptomatic or symptomatic pregnant women, cervicovaginal fetal fibronectin testing before 37 weeks' gestation, known gestation at spontaneous birth, and observational cohort design. Studies were selected in a two stage process. Two us (HH and LMB) independently scrutinised the electronic searches and obtained full manuscripts of all citations that were likely to meet the predefined selection criteria. Final inclusion or exclusion decisions were then made after we examined these manuscripts. In cases of duplicate publication we selected the most recent and complete versions. We had no language restrictions, but we excluded case-control studies. Two of us (HH and LMB) independently assessed English, French, and Spanish manuscripts. LMB assessed German manuscripts, while other language manuscripts were assessed by people who had command of the language to allow
Total citations identified from electronic searches to capture primary articles on all tests for predicting preterm birth $(n=30076)$ Citations excluded after screening titles and/or abstracts $(n=29$ 987)

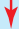

Primary articles on cervicovaginal fetal fibronectin test accuracy retreived for detailed evaluation $(n=116)$

From electronic search $\quad(n=89)$

From reference lists $\quad(n=26)$

Contact with manufacturer $(n=2)$ (from company's website www.adeza.com)

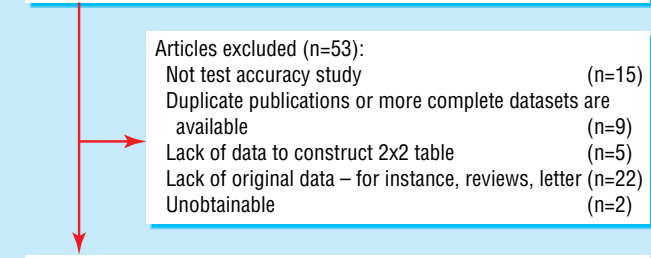

Primary articles included in systematic review $(\mathrm{n}=64)$

No of studies included in these articles $(n=68)$

\begin{tabular}{l|l|}
\hline \multicolumn{1}{|c|}{} & \multicolumn{1}{|c|}{} \\
\hline Studies on asymptomatic & Studies on symptomatic \\
women ( $\mathrm{n}=28)$ & women ( $\mathrm{n}=40)$ \\
Low risk (8 studies) & Low risk (5 studies) \\
High risk (9 studies) & High risk (4 studies) \\
Risk not categorised (11 studies) & Risk not categorised (31 studies) \\
\hline
\end{tabular}

Fig 1 Study selection process for systematic review of cervicovaginal fetal fibronectin test see webextra for list of excluded studies (total number of studies (68) exceeds 64 because some primary articles provided data on more than one study)

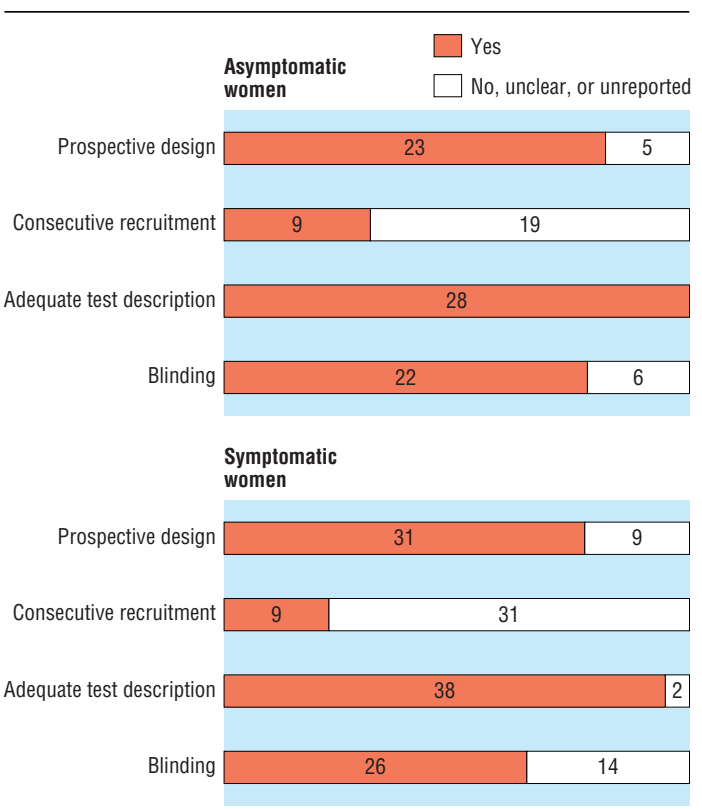

Fig 2 Methodological quality of studies included in the systematic review. Data presented as 100\% stacked bars; figures in the stacks represent number of studies

data extraction from the manuscripts. We resolved any disagreements about inclusion or exclusion by consensus or arbitration by a third reviewer (KSK).

We extracted study characteristics, quality, and accuracy of results from each selected article. Study characteristics consisted of women's risk classifications, test characteristics, and reference standards of the test. In studies where multiple tests were performed, we 


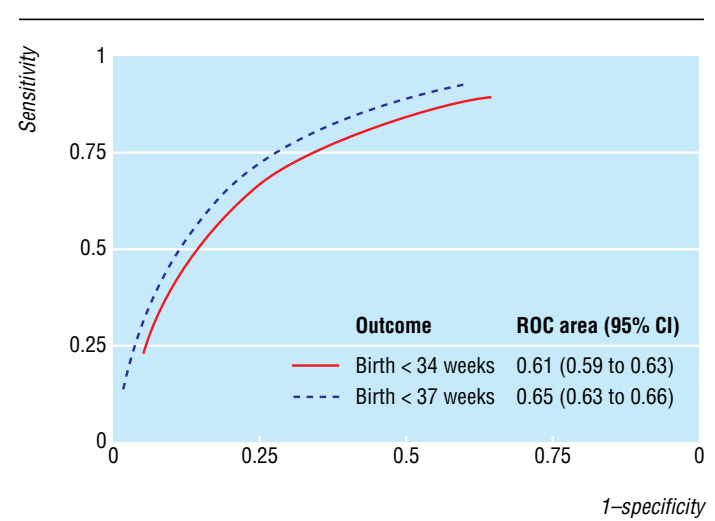

Fig 3 Summary receiver operating characteristic (ROC) curves for cervicovaginal fetal fibronectin test in predicting spontaneous preterm birth in asymptomatic women

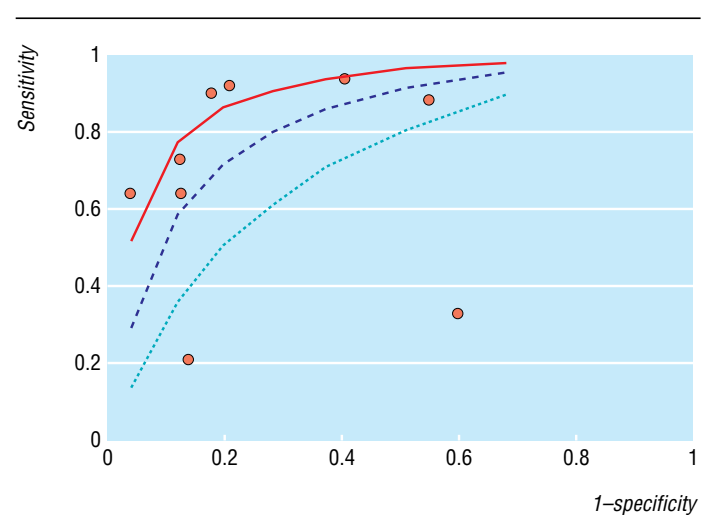

Fig 4 ROC curve (with 95\% confidence interval boundaries) for individual study results for test predicting spontaneous preterm birth at 34 weeks' gestation in asymptomatic women

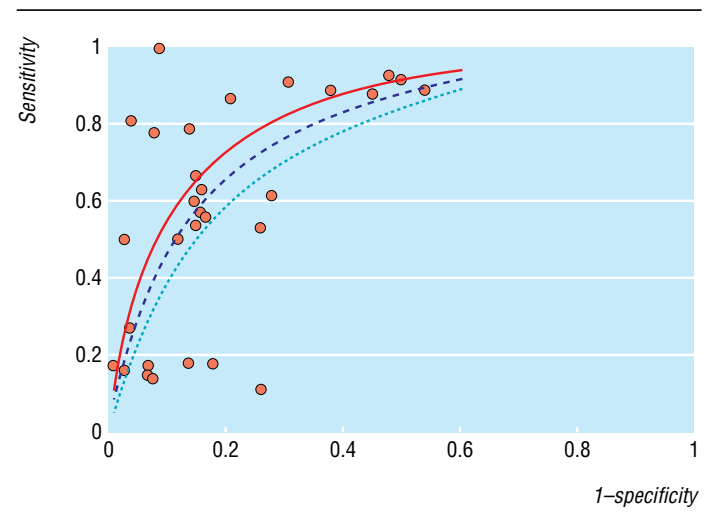

Fig 5 ROC curve (with 95\% confidence interval boundaries) for individual study results for test predicting spontaneous preterm birth at 37 weeks' gestation in asymptomatic women

considered any positive result as a positive result overall. Accuracy data were used to construct $2 \times 2$ tables of test results and spontaneous preterm birth, which served as the reference standard. We extracted data for asymptomatic and symptomatic women on spontaneous preterm birth before 34 and 37 weeks' gestation. In addition, for symptomatic women we extracted data on spontaneous preterm birth within 7-10 days of testing. We piloted and tested the data extraction form for repeatability on the first eight manuscripts. ${ }^{20-27}$ Overall, the observer agreement regarding the various components of the data extraction form was $90-100 \%$, with $x$ values ranges from 0.9 to 1.0 .

\section{Assessment of study quality}

We assessed all manuscripts that met the selection criteria for study quality. We defined quality as the confidence that the study design, conduct, and analysis minimised bias in the estimation of test accuracy. Bias can be associated with case-control study designs, lack of blinding of carer to test results, non-consecutive patient enrolment, non-prospective data collection, inadequate test description, use of different reference tests, partial verification, and lack of description of either the population or the reference test. ${ }^{28}$ The last four items, however, are not relevant to our review because they refer to delivery of neonates (preterm or term births). Therefore, we considered a study to be of good quality if it used a prospective design, consecutive enrolment, adequate test description (to allow replication by others), and blinding of the test result from clinicians managing the patients. ${ }^{29}$

\section{Data synthesis}

We synthesised data separately for studies on asymptomatic and symptomatic women with spontaneous preterm birth before 34 and 37 weeks' gestation. For symptomatic women we also synthesised data for spontaneous preterm birth within 7-10 days of testing. We assessed heterogeneity of diagnostic odds ratios graphically (using forest ${ }^{30}$ and Galbraith plots $^{31}$ ) and statistically (using $\chi^{2}$ test) to help us to decide how to proceed with quantitative synthesis. ${ }^{32}$ For each outcome within the two populations there was significant heterogeneity. We explored possible sources of heterogeneity by meta-regression analysis ${ }^{16}$ using various independent explanatory variables defined a priori. These variables were risk classifications (high or low as defined by the authors), multiple gestation (included or excluded), type of recruitment (consecutive or others), digital examination before testing (yes or no), sexual intercourse within 24 hours preceding testing (yes or no), bleeding before testing (yes or no), methods of testing (laboratory or bedside), serial testing (yes or no), gestation at testing for asymptomatic women (before or after 24 weeks), blinding of test results (yes or no), study design (prospective or retrospective), and publication language (English or other). When a variable was not explicitly mentioned, it was treated as "no" in the meta-regression analysis. As our metaregression analysis failed to explain the observed heterogeneity we proceeded with meta-analysis using random effects model. ${ }^{33}$ Consequently, the pooled results should be interpreted with caution. To aid in interpretation we examined the estimate of accuracy of the highest quality studies included in our review.

We used summary receiver operating characteristic (ROC) curves $^{34}$ as measures of accuracy for all included studies regardless of their thresholds. The area under the curve provides an average measure of accuracy from the combined studies (especially when there are different test thresholds) and a convenient way of comparing accuracy of the test for different outcomes. ${ }^{35} \mathrm{We}$ used summary likelihood ratios as measures of accuracy for studies using $50 \mathrm{ng} / \mathrm{ml}$ as the threshold. These ratios indicate by how much a given test result 


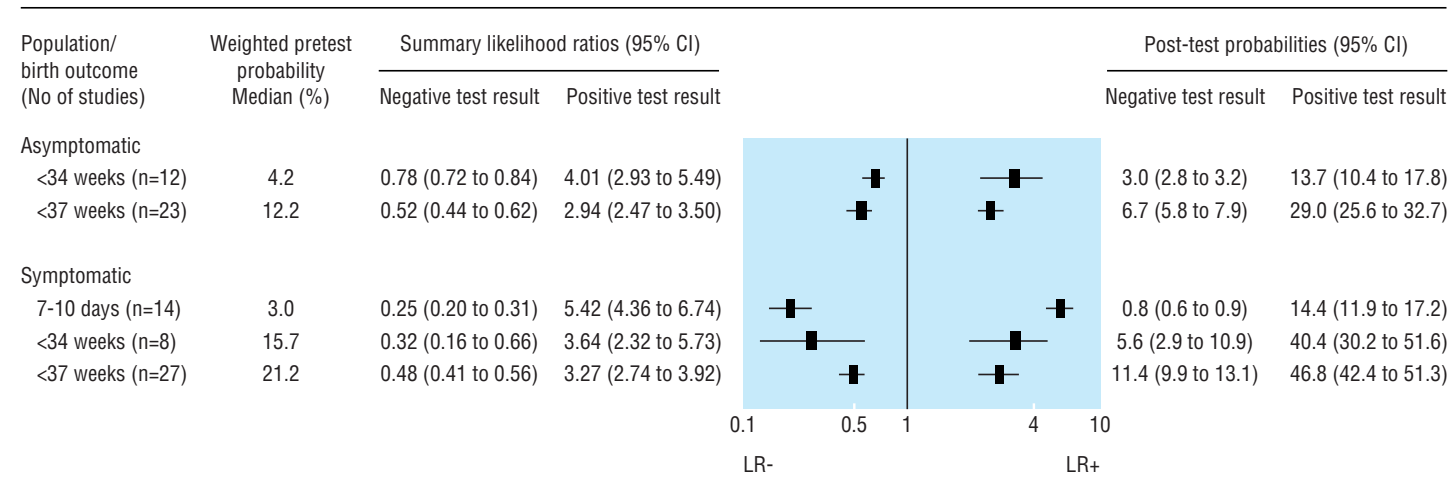

Fig 6 Pooled estimates of likelihood ratios for cervicovaginal fetal fibronectin test and their impact on predictive probabilities of spontaneous preterm birth in asymptomatic and symptomatic women (as for ROC if this pooled one is kept in short can refer to sep forest plots in long version)

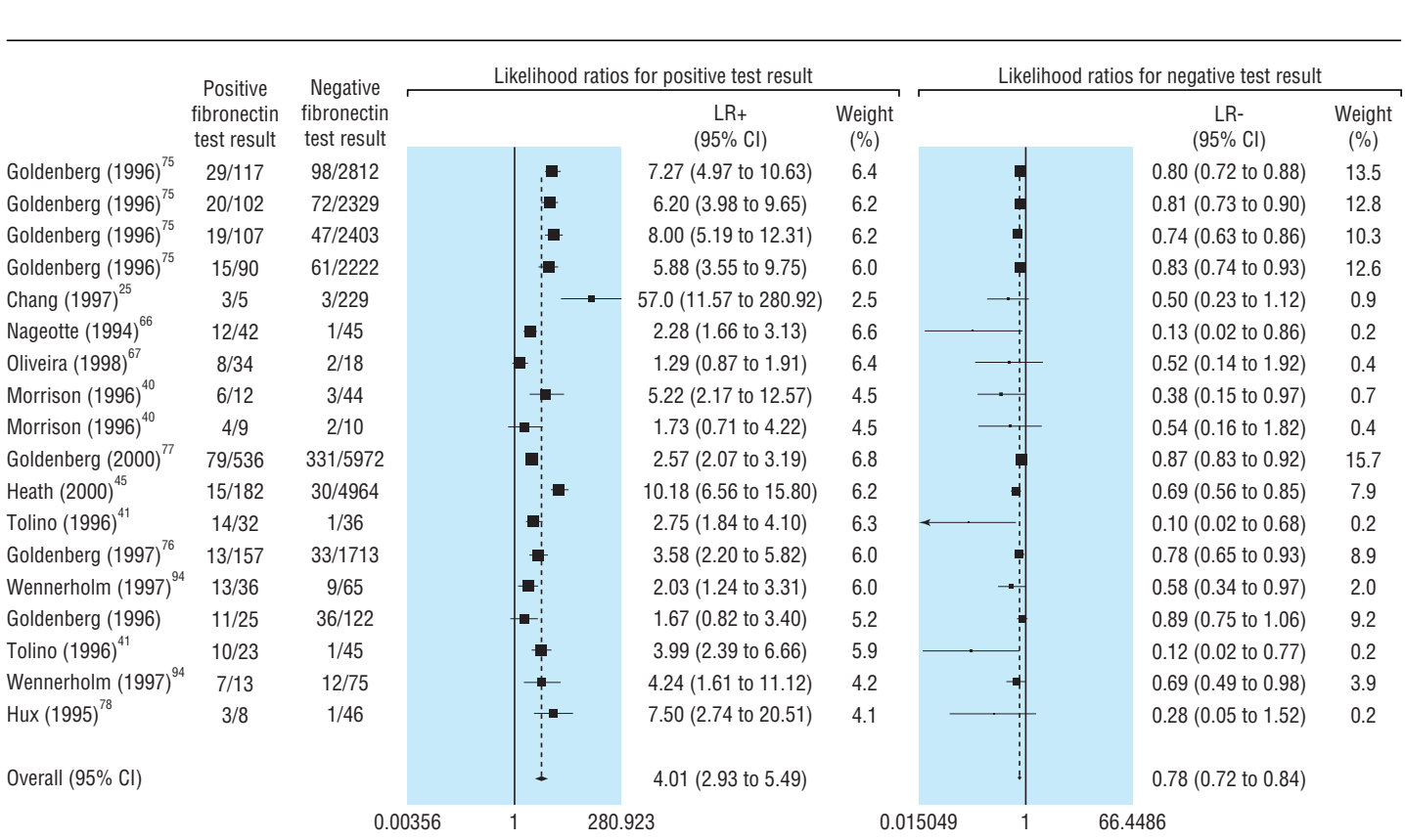

Fig 7 Likelihood ratios for positive and negative test results for studies predicting spontaneous preterm birth before 34 weeks' gestation in asymptomatic women

will raise or lower the probability ${ }^{36}$ of having a spontaneous preterm birth. Using summary ratios we determined probabilities after the test by Bayes's theorem as follows ${ }^{36}$ :

post-test probability $=$ ratio $\times$ pretest probability/

$[1-$ pretest probability $\times(1-$ ratio $)]$.

In this way, ratios are more clinically meaningful than sensitivities or specificities, for which meta-analysis are generally not recommended. ${ }^{37}$ To detect publication and related bias, we undertook funnel plot (diagnostic odds ratio $v$ reciprocal of its standard error) analysis. ${ }^{38}$ All statistical analyses were performed with SPSS version 10 and Stata 7.0 statistical packages.

\section{Results}

Literature identification and study quality

Figure 1 summarises the process of literature identification and selection. Sixty four primary articles met the selection criteria. (The references we excluded from analysis can found on webextra.) They consisted of 28 accuracy studies in asymptomatic women and 40 studies in symptomatic women, with a total of 26876 women. The webextra table summarises each study's salient features according to whether the women were asymptomatic or symptomatic and their risk classifications. Figure 2 summarises the quality of methods. Thirteen (19\%) studies, seven among asymptomatic ${ }^{39-45}$ and six among symptomatic women, ${ }^{46-51}$ fulfilled all four criteria for good quality. All studies except three $^{52-54}$ (which accounted for $0.28 \%$ of the 22390 women in our review) used thresholds of $50 \mathrm{ng} / \mathrm{ml}$ to indicate an abnormal test result. ${ }^{8}$

\section{Fibronectin test in asymptomatic women}

In women without symptoms three studies examined the accuracy of the test using bedside methods and 26 used laboratory methods. Thirteen studies examined single testing and 16 looked at serial testing. Eight studies examined the use of fibronectin as a screening tool in low risk pregnancy and nine as a selective screening tool in high risk pregnancy. Most studies 


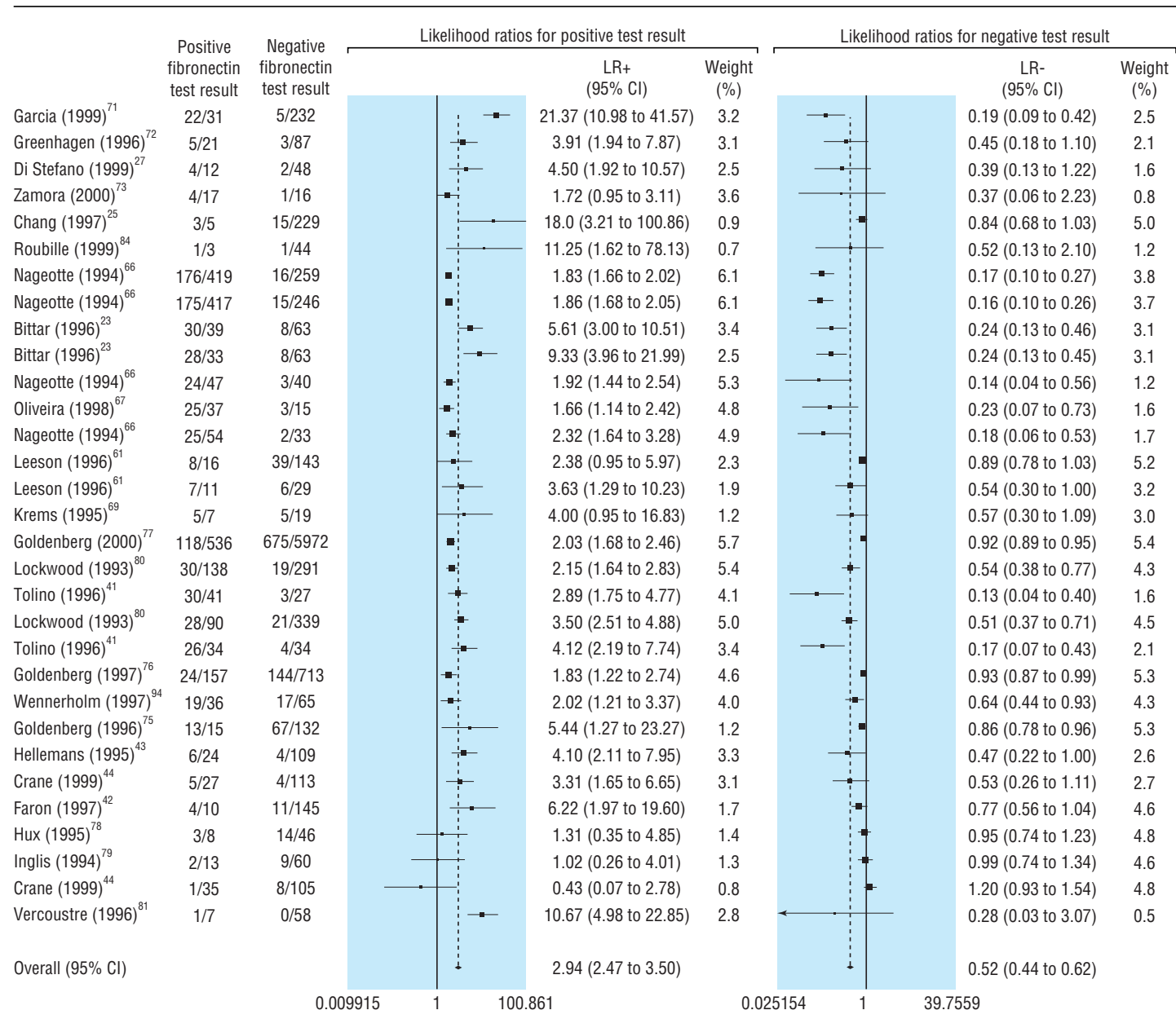

Fig 8 Likelihood ratios for positive and negative test results for studies predicting spontaneous preterm birth before 37 weeks' gestation in asymptomatic women

were carried out during the second trimester or early in the third trimester. Meta-regression analysis showed the accuracy of the test did not depend on the method of testing, how often the test was done, classification of risk, or gestation at testing.

The estimates of the accuracy of the test in predicting spontaneous preterm birth for the various gestations of interest varied considerably. Figure 3

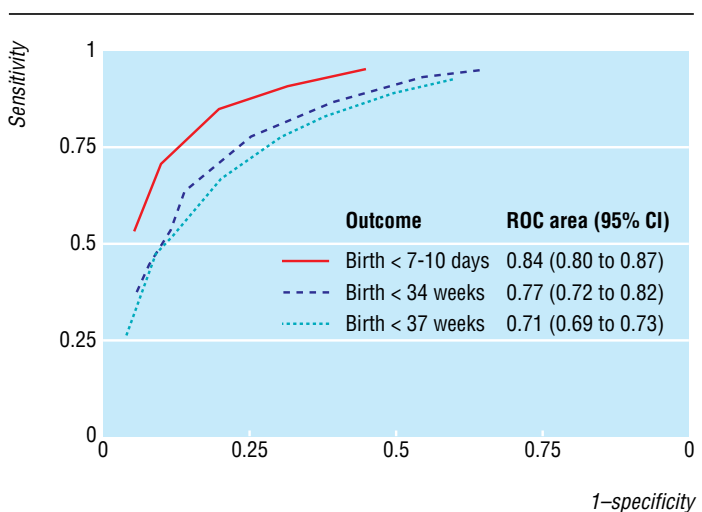

Fig 9 Summary receiver operating characteristic (ROC) curves and areas for cervicovaginal fetal fibronectin test in predicting spontaneous preterm birth symptomatic women shows the summary receiver operating characteristic curve for asymptomatic women. Figures 4 and 5 show individual study results used to create the summary curve. Figure 6 shows the pooled estimates of likelihood ratios. Figures 7 and 8 show details from individual studies.

When we examined study quality as a source of heterogeneity we found no significant differences in estimates of accuracy in studies with high and low quality features. The estimates of accuracy of studies that fulfilled all four of the quality criteria were generally consistent with the pooled results. For example, the median likelihood ratios for predicting spontaneous preterm birth before 34 weeks' gestation among the five highest quality studies were 3.99 (interquartile range 1.73-10.18) for a positive result and 0.38 (0.10-0.69) for a negative result.

\section{Fibronectin test in symptomatic women}

In women with symptoms 11 studies examined the accuracy of the test using bedside methods and 30 used laboratory methods. Thirty five examined occasion testing, and five looked at serial testing. Metaregression analysis showed that the accuracy of the test did not depend on the method of testing, how often the test was done, or classification of risk. As for asymptomatic women, the accuracy of the in predicting spon- 


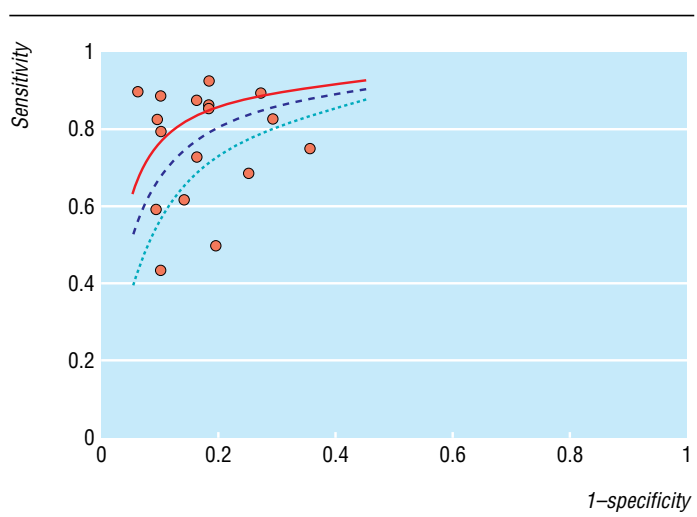

Fig 10 ROC curve (with 95\% confidence interval boundaries) for individual study results for cervicovaginal fetal fibronectin test in predicting spontaneous preterm birth 7-10 days after testing in symptomatic women

taneous preterm birth for the various gestations of interest varied considerably. Figure 9 shows the summary receiver operating characteristic curve for symptomatic women. Figures 10, 11, and 12 give details of individual results used to create the summary curve. The pooled estimate of the likelihood ratios can be found in figure 6 , with details of individual studies in figures 13,14 , and 15 .

When we examined study quality as a source of heterogeneity we found no significant differences in estimates of accuracy in studies with high and low quality features. The estimates of accuracy of studies that fulfilled all four of the quality criteria were generally consistent with the pooled results. For example, the median likelihood ratios for predicting for predicting spontaneous preterm birth within 7-10 days of testing among the four highest quality studies were 6.16 (4.537.33) for a positive result and $0.32(0.01-0.45)$ for a negative result.

Cervicovaginal fetal fibronectin testing among symptomatic women and number of women needed to be treated (NNT) at 31 weeks' gestation with antenatal steroids to prevent one case of neonatal respiratory distress syndrome (RDS) associated with spontaneous preterm birth within 7-10 days of testing

\begin{tabular}{lcccr} 
Test result & $\begin{array}{c}\text { Probability of } \\
\text { spontaneous preterm } \\
\text { birth within 7-10 days } \\
\text { of testing (\%) }\end{array}$ & $\begin{array}{c}\text { Risk of RDS at } \\
\mathbf{3 2} \text { weeks' }^{\text {gestation }} \mathbf{5 6}\end{array}$ & $\begin{array}{c}\text { 57 } \\
\text { Rete of RDS* at 32 } \\
\text { weeks' gestation (\%) }\end{array}$ & NNT† \\
\hline No testing & $4.5 \ddagger$ & 0.53 & 2.0 & 109 \\
\hline Test positive & $20.6 \S$ & 0.53 & 11.0 & 17 \\
\hline Test negative & $1.0 \S$ & 0.53 & 0.4 & 509
\end{tabular}

${ }^{*}$ Calculated as probability of spontaneous preterm birth for positive test result at 32 weeks (31 weeks $+7-10$ days) $=20.6 \%$. Risk of RDS at this gestation $=0.53^{56 ; 57}$, therefore, probability of RDS in neonate of woman with positive result=20.6 x $0.53=11 \%$ (similar calculation may be carried out for negative result). t For example, rate of RDS at 32 weeks' gestation $=11 \%$, converted to odds of RDS without treatment $=11 /(100-11)=0.12$. Odds of treatment benefit $=0.12 \times 0.53=0.064$ (where 0.53 is odds ratio fo treatment benefit of antenatal steroids, obtained from Cochrane review, ${ }^{6}$ which coincidentally, is the same figure as the risk for RDS at 32 weeks' gestation), converted to rate of RDS after antenatal steroid treatment $=0.064 /(1+0.064)=0.059$. Rate difference of RDS between treatment and without antenatal steroid treatment $=0.12-0.059=0.061$ and number need to treat is $1 / 0.061=17$. This means that with positive test results, 17 symptomatic women who presented at 31 weeks' gestation need to be treated with antenatal steroids to prevent one case of RDS (similar calculation may be carried out for negative test result). $\ddagger$ Pretest probability of spontaneous preterm birth within 7-10 days of testing for symptomatic women presenting at 31 weeks' gestation..$^{21: 22 ; 46 ; 50 ; 51 ; 58-65}$ (see webextra table).

§Calculation of probabilities with likelihood ratios shown in figure 6: pretest probability (4.5\%) converted to pretest odds $=4.5 /(100-4.5)=0.047$; post-test odds for spontaneous preterm birth among women with a positive test=pretest $0 \mathrm{dds} \times \mathrm{LR}+=0.047 \times 5.45=0.26$ ( $\mathrm{LR}+$ indicates likelihood ratio for positive result). This is then converted to post-test probability $=0.26 /(0.26+1)=0.206=20.6 \%$ (a similar calculation may be carried out for negative test result using LR- found in figure 6).
Funnel plot analysis showed no evidence of asymmetry that would indicate presence of publication or related bias for the main outcomes.

\section{Discussion}

Our results show that the accuracy of the cervicovaginal fetal fibronectin in predicting various spontaneous preterm birth outcomes varies. The test is most accurate in predicting spontaneous preterm birth within 7-10 days after testing among women with symptoms of threatened preterm birth before advanced cervical dilatation.

\section{Quality of our review}

The strength of our inferences depends on the rigour of our methods. In contrast with the previous four systematic reviews ${ }^{12-15}$ we identified 64 studies (at least twice as many studies as the largest previous review ${ }^{14}$ ) because we did not limit our search to a single database $^{13} 15$ nor did we apply language restrictions. ${ }^{13}$ Because meta-analysis of studies that examine test accuracy are fraught with difficulty owing to poor methodological quality of the primary studies, we scrutinised the selected studies for their quality, an assessment undertaken in only one previous review. ${ }^{15}$ Methodological issues that may overestimate accuracy

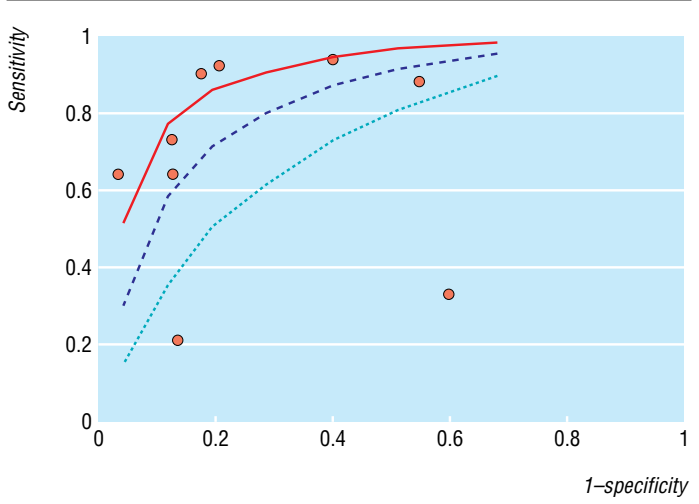

Fig 11 ROC curve (with 95\% confidence interval boundaries) for individual study results for cervicovaginal fetal fibronectin test in predicting spontaneous preterm birth before 34 weeks' gestation in symptomatic women

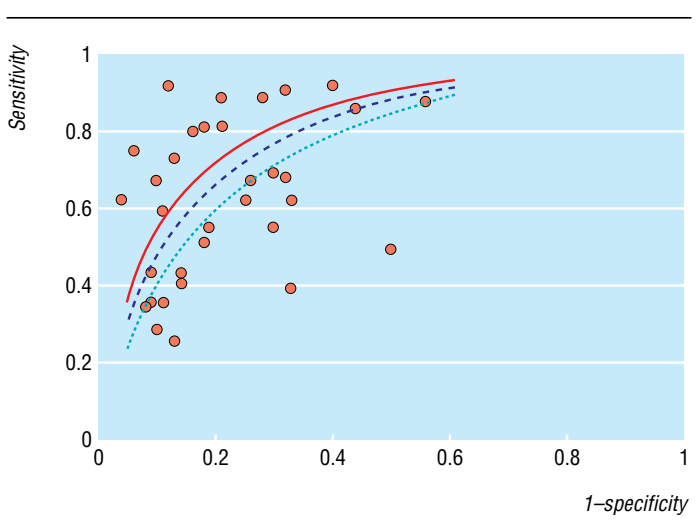

Fig 12 ROC curve (with 95\% confidence interval boundaries) for individual study results for cervicovaginal fetal fibronectin test in predicting spontaneous preterm birth before 37 weeks' gestation in symptomatic women 


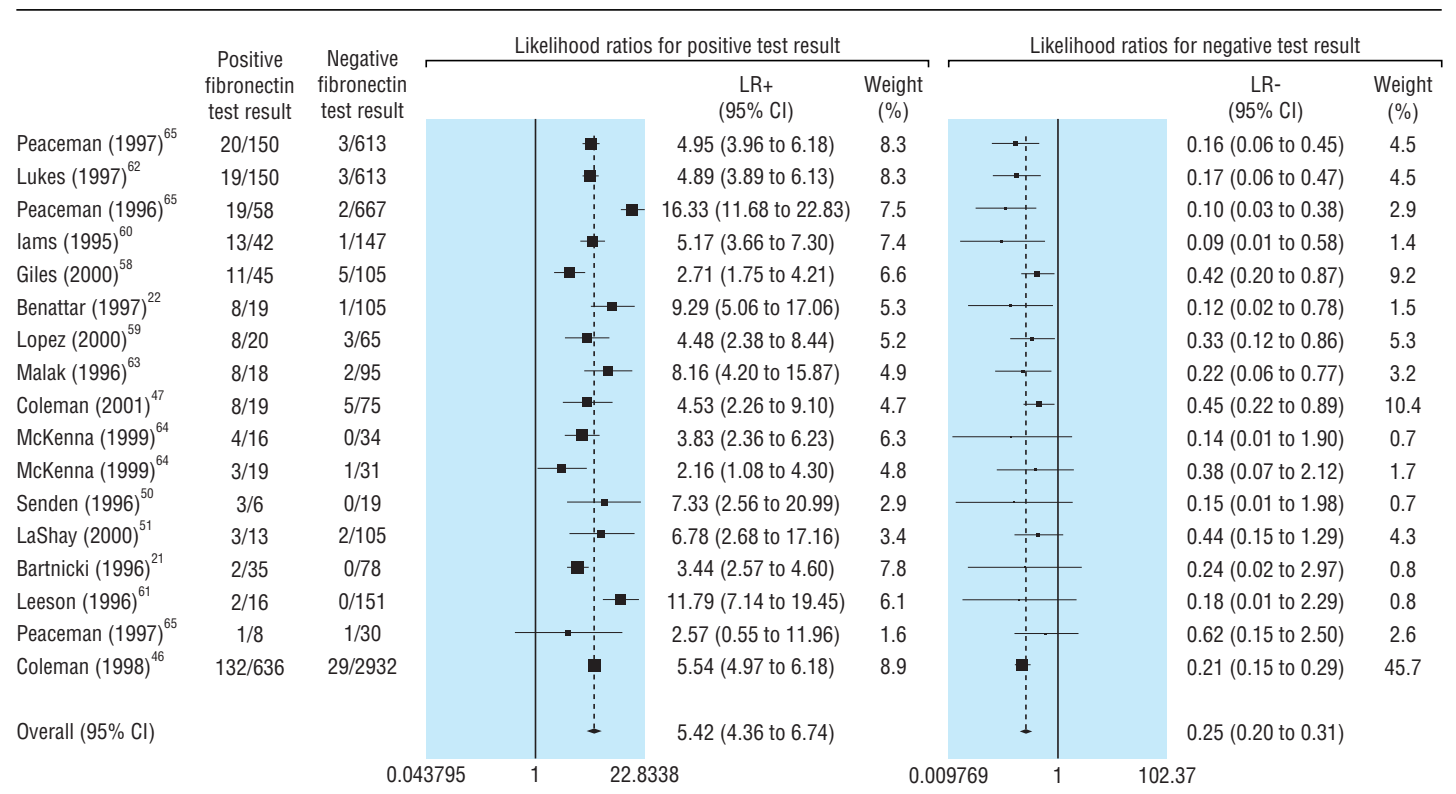

Fig 13 Likelihood ratios for positive and negative test results for studies predicting spontaneous preterm birth 7-10 days after testing in symptomatic women

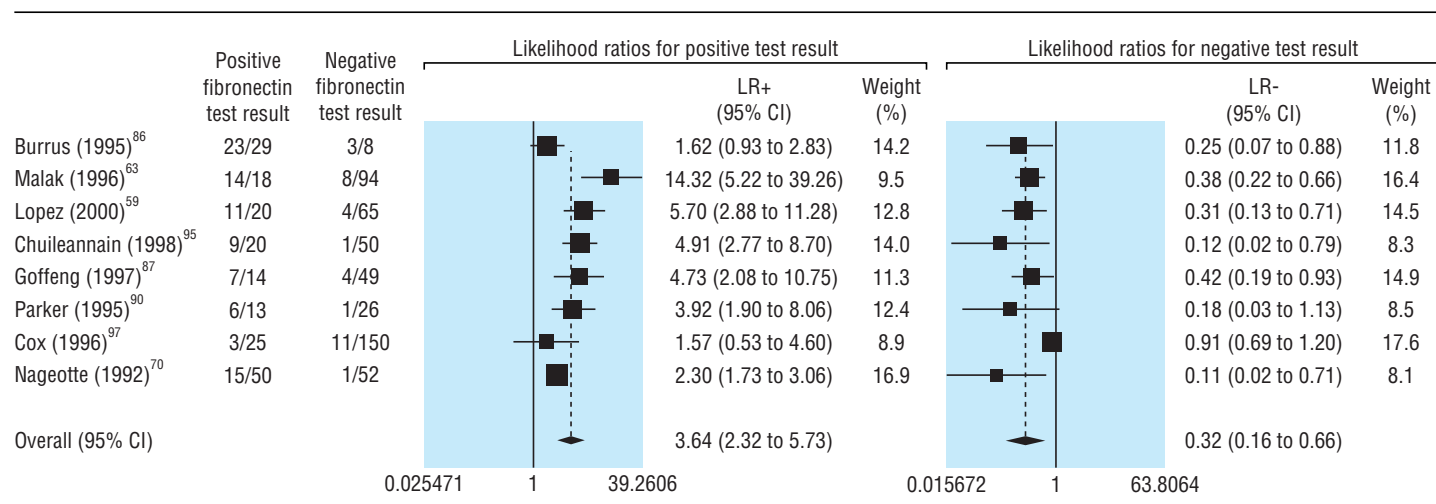

Fig 14 Likelihood ratios for positive and negative test results for studies predicting spontaneous preterm birth before 34 weeks' gestation in symptomatic women

such as case-control design, absence of test descriptions, and different reference tests, ${ }^{28}$ were not applicable to the studies we reviewed. Our assessments of quality were affected by poor reporting in some instances, though quality did not significantly explain differences between their results. Assessment and exploration for reasons behind heterogeneity were planned a priori. In the presence of unexplained heterogeneity we pooled data with a random effects model, which produces a wider confidence interval. ${ }^{16}$ However, due to the large number of studies the estimates of accuracy were generally more precise compared with previous reviews.

\section{Clinical application}

The clinical impact of the estimates of accuracy that we have produced depends on how the resultant changes in probabilities due to fibronectin testing alter therapeutic effectiveness in decision making. ${ }^{55}$ We can illustrate this impact with an example of decision making about the use of antenatal steroids in women with symptoms of threatened preterm birth at 31 weeks' gestation (table). ${ }^{6}$ The absolute effect of antenatal ster- oids depends on the risk of spontaneous preterm birth after presentation. The higher the risk, the lower the number of women that needed to be treated to prevent one case of respiratory distress syndrome and vice versa. The risk, and hence the therapeutic benefits, depends not only on the gestational age at presentation but also on the post-test probabilities of spontaneous preterm birth associated with fibronectin testing. As shown in the table, if steroids were to be used for all symptomatic women at this gestation without fibronectin testing then we would need to treat 109 women with antenatal steroids to prevent one case of respiratory distress syndrome. If we treated only those women with a positive test result we would need to treat 17 , a figure considerably lower than that without testing

This approach will allow clinicians to make explicit decisions on the basis of more realistic probabilities generated by fibronectin testing and provides a framework for the use of diagnostic evidence in therapeutic decision making. Specifically, our results enable clinicians to make a more rational approach to 


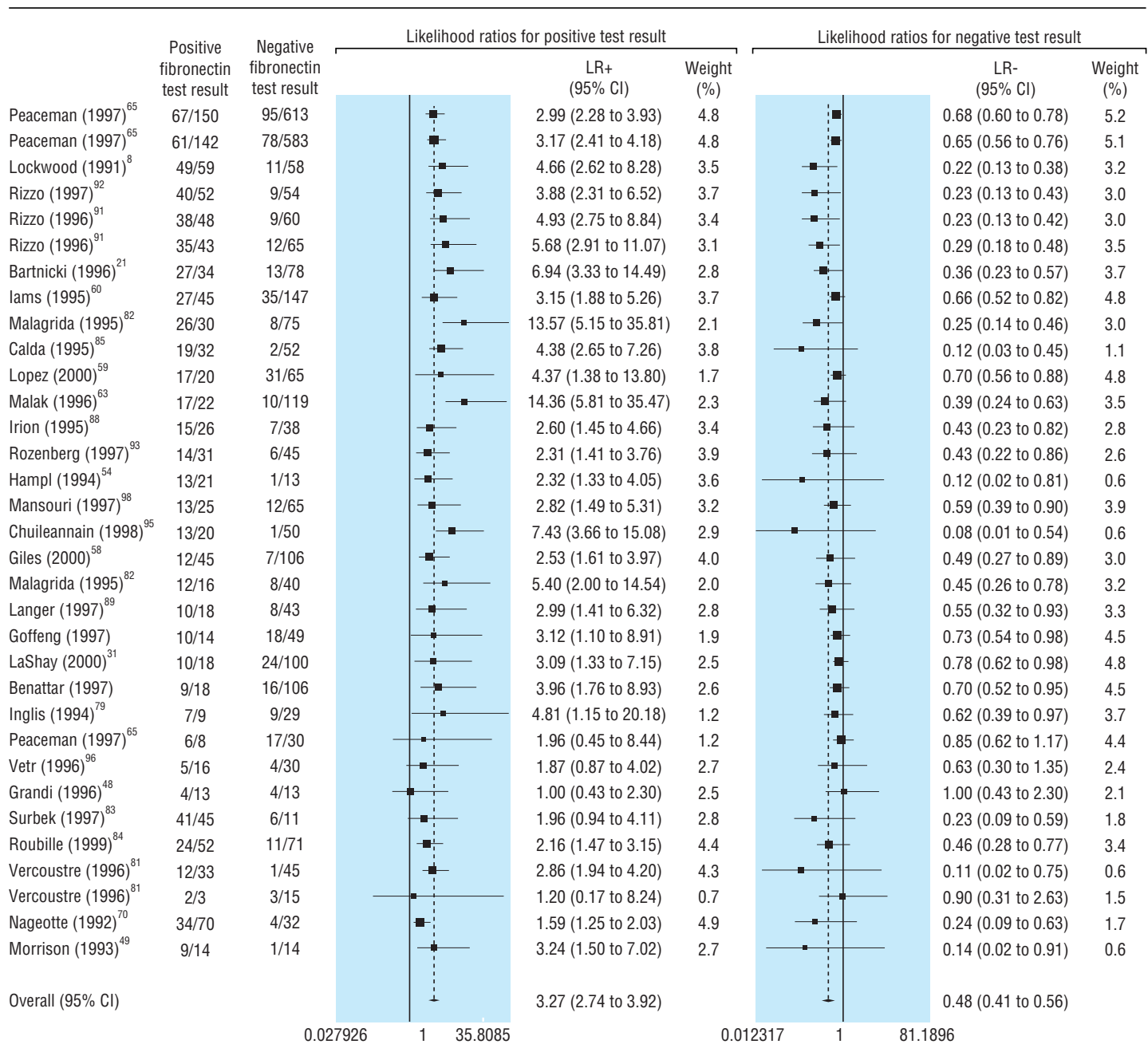

Fig 15 Likelihood ratios for positive and negative test results for studies predicting spontaneous preterm birth before 37 weeks' gestation in symptomatic women

decision making regarding inpatient admission, administration of antenatal steroids, and in utero transfer in women with threatened spontaneous preterm birth. Future research should focus on undertaking high quality primary studies of test accuracy to improve our ability to predict spontaneous preterm birth.

We thank Fujian Song, Malgorzata Adamcyzck, and Pavlina Jungova for their help in extracting relevant data from Chinese, Polish, and Czech manuscripts, respectively. We also thank Julie Glanville and Stephen Duffy at the NHS Centre for Reviews and Dissemination at York for contribution to the database searches. We are grateful to Professor R Zimmermann, Professor M J Whittle, and Mr H Gee for their critical review of the manuscript and for suggestions for improvement.

Contributors: KSK, JKG, and JK conceived the review. HH, LMB, and KSK collected, analysed, and interpreted the data and drafted the manuscript. JK and JKG made critical revisions. KSK, LMB, and HH are the guarantors.

Funding: WellBeing grant No K2/00

Competing interests: None declared.

1 Maternal and Child Health Consortium. Comfidential enquiries into stillbirths and deaths in infancy (CESDI): 6th annual report. London: Stationery Office, 1999

2 Peters KD, Kochanek KD, Murphy SL. Deaths: final data for 1996. Natl Vital Stat Rep 1998;47:1-100.

3 Department of Health (UK). NHS maternity statistics, England: $1989-90$ to 1994-95. London: Stationery Office, 1997. www.doh.gov.uk/public/ sb9728.htm (accessed 23 August 2001).

\section{What is already known on this topic}

Spontaneous preterm birth is a major cause of neonatal morbidity and mortality

If spontaneous preterm birth can be predicted, effective therapeutic strategies can be used to improve neonatal outcomes

Though the cervicovaginal fetal fibronectin test has been proposed as a predictive test, estimates of its accuracy are variable

\section{What this study adds}

The cervicovaginal fetal fibronectin test is most accurate in predicting spontaneous preterm birth within 7-10 days of testing among women with symptoms of threatened preterm birth before advanced cervical dilatation

After a positive test result 17 symptomatic women at 31 weeks' gestation would need to be treated with antenatal steroids to prevent one case of respiratory distress syndrome 
4 Stewart AL, Rifkin L, Amess PN, Kirkbride V, Townsend JP, Miller DH, et al. Brain structure and neurocognitive and behavioural function in adolescents who were born very preterm. Lancet 1999;353:1653-7.

5 Wolke D, Meyer R. Cognitive status, language attainment, and prereading skills of 6-year-old very preterm children and their peers: the Bavarian longitudinal study. Dev Med Child Neurol 1999:41:94-109.

6 Crowley P. Prophylactic corticosteroids for preterm birth. Cochrane Database Syst Rev 2000;(2):CD000065

7 Matsuura H, Takio K, Titani K, Greene T, Levery SB, Salyan ME, et al. The oncofetal structure of human fibronectin defined by monoclonal antibody FDC-6. Unique structural requirement for the antigenic specificity provided by a glycosylhexapeptide. J Biol Chem 1988;263:3314-22.

8 Lockwood CJ, Senyei AE, Dische MR, Casal D, Shah KD, Thung SN, et al. Fetal fibronectin in cervical and vaginal secretions as a predictor of preterm delivery. N Engl J Med 1991;325:669-74

Sadovsky Y, Friedman SA. Fetal fibronectin and preterm labor. $N$ Engl J Med 1992;326:709.

10 Shimoya K, Hashimoto K, Shimizu T, Saji F, Murata Y. Effect of sexual intercourse on fetal fibronectin concentration in cervicovaginal secretions. Am J Obstet Gynecol 1998;179:255-6.

11 Brubaker DB, Ross MG, Marinoff D. The function of elevated plasma fibronectin in preeclampsia. Am J Obstet Gynecol 1992;166:526-31.

12 Leitich H, Egarter C, Kaider A, Hohlagschwandtner M, Berghammer P, Husslein P. Cervicovaginal fetal fibronectin as a marker for preterm delivery: a meta-analysis. Am J Obstet Gynecol 1999;180:1169-76.

13 Revah A, Hannah ME, Sue-A Quan AK. Fetal fibronectin as a predictor of preterm birth: an overview. Am J Perinatol 1998;15:613-21.

14 Faron G, Boulvain M, Irion O, Bernard PM, Fraser WD. Prediction of preterm delivery by fetal fibronectin: a meta-analysis. Obstet Gynecol 1998;92:153-8.

15 Chien PFW, Khan KS, Ogston S, Owen P. The diagnostic accuracy of cervico-vaginal fetal fibronectin in predicting preterm delivery: an overview. Br J Obstet Gynaecol 1997:104:436-44.

16 Song F, Sheldon T, Sutton AJ, Abrams KR, Jones DR. Methods for exploring heterogeneity in meta-analysis. Eval Health Prof 2001;24:12651 .

17 Cochrane methods group on systematic review of screening and diagnostic tests: recommended methods, last updated on 6 June 1996. www.cochrane.org/cochrane/sadtdoc1.htm (accessed 7 April 2001).

18 Khan KS, Dinnes J, Kleijnen J. Systematic reviews to evaluate diagnostic tests. Eur J Obstet Gynecol Reprod Biol 2001;95:6-11.

19 Honest H, Bachmann LM, Khan KS Electronic searching of the literature for systematic reviews of screening and diagnostic tests for preterm birth. Eur J Obstet Gynecol Reprod Biol (in press).

20 Ascarelli $\mathrm{MH}$, Morrison JC. Use of fetal fibronectin in clinical practice. Obstet Gynecol Surv 1997;52(suppl 4):S1-12.

21 Bartnicki J, Casal D, Kreaden US, Saling E, Vetter K. Fetal fibronectin in vaginal specimens predicts preterm delivery and very-low-birth-weight infants. Am J Obstet Gynecol 1996;174:971-4

22 Benattar C, Taieb J, Fernandez H, Lindendaum A, Frydman R, Ville Y Rapid fetal fibronectin swab-test in preterm labor patients treated by betamimetics. Eur J Obstet Gynecol Reprod Biol 1997;72:131-5.

23 Bittar RE, Yamasaki AA, Sasaki S, Zugaib M. Cervical fetal fibronectin in patients at increased risk for preterm delivery. Am J Obstet Gynecol 1996:175:178-81.

24 Bon C, Roubille M, Mailliavin A, Pichot J. Fetal fibronectin detection for prediction of preterm delivery. Immuno Anal Biol Spec 2000;15:96-108.

25 Chang TC, Chew TS, Pang M, Tan AC, Yeo GS. Cervicovaginal foeta fibronectin in the prediction of preterm labour in a low-risk population. Ann Acad Med Singapore 1997;26:776-80.

26 Daskalakis GJ, Papantoniou NE, Koutsodimas NB, Papapanagiotou A, Antsaklis AJ. Fetal fibronectin as a predictor of preterm birth. J Obstet Gynaecol 2000;20:347-53.

27 DiStefano L, Carta G, Di Paolantonio L, Palerno P, Moscarini M. Preterm delivery: Predictive value of cervico-vaginal fetal fibronectin. Clin Exp Obstet Gynecol 1999;26:187-9.

28 Lijmer JG, Mol BW, Heisterkamp S, Bonsel GJ, Prins MH, van der Meulen JH, et al. Empirical evidence of design-related bias in studies of diagnostic tests. JAMA 1999;282:1061-6.

29 Khan KS, ter Riet G, Popay J, Nixon J, Kleijnen J. Study quality assessment (phase 5): conducting the review (stage 2). Undertaking systematic reviews of research on effectiveness. 1-20. York: University of York, 2001 (CRD Report No 4).

30 DerSimonian R, Laird N. Meta-analysis in clinical trials. Control Clin Trials $1986 ; 7: 177-88$

31 Galbraith RF. A note on graphical presentation of estimated odds ratios from several clinical trials. Stat Med 1988;7:889-94.

32 Greenland S. Quantitative methods in the review of epidemiologic literature. Epidemiol Rev 1987;9:1-30.

33 Sutton AJ, Abrams KR, Jones DR, Sheldon TA, Song F. Systematic reviews of trials and other studies. Health Technol Assess 1998;2:1-276.

34 Moses LE, Shapiro D, Littenberg B. Combining independent studies of a diagnostic test into a summary ROC curve: data analytic approaches and some additional considerations. Stat Med 1993;12:1293-316.

35 de Vries SO, Hunink MG, Polak JF. Summary receiver operating characteristic curves as a technique for meta-analysis of the diagnostic performance of duplex ultrasonography in peripheral arterial disease. Acad Radiol 1996;3:361-9.

36 Jaeschke R, Guyatt G, Sackett DL. Users' guides to the medical literature III. How to use an article about a diagnostic test. B. What are the result and will they help me in caring for my patients? The evidence-based medicine working group. JAMA 1994;271:703-7.

37 Rutter CM, Gatsonis CA. A hierarchical regression approach to meta-analysis of diagnostic test accuracy evaluations. Stat Med 2001;20:2865-84.
38 Song F, Khan KS, Dinnes J, Sutton A. Asymmetric funnel plots and publication bias in meta-analyses of diagnostic accuracy. Int $J$ Epidemio 2002;31:88-95

39 Goldenberg RL, Iams JD, Miodovnik M, Van Dorsten JP, Thurnau G, Bottoms S, et al. The preterm prediction study: risk factors in twin gestations. National Institute of Child Health and Human Development Maternal-Fetal Medicine Units Network. Am J Obstet Gynecol $1996 ; 175: 1047-53$.

40 Morrison JC, Naef RW 3rd, Botti JJ, Katz M, Belluomini JM, McLaughlin BN. Prediction of spontaneous preterm birth by fetal fibronectin and uterine activity. Obstet Gynecol 1996;87:649-55.

41 Tolino A, Ronsini S, Zullo F, Pellicano M, Regine V, Nappi C. Fetal fibronectin as a screening test for premature delivery in multiple pregnancies. Int J Gynaecol Obstet 1996;52:3-7.

42 Faron G, Boulvain M, Lescrainier JP, Vokaer A. A single cervical feta fibronectin screening test in a population at low risk for preterm delivery: an improvement on clinical indicators? Br J Obstet Gynaecol 1997; 104:697-701.

43 Hellemans P, Gerris J, Verdonk P. Fetal fibronectin detection for prediction of preterm birth in low risk women. Br J Obstet Gynaecol $1995 ; 102: 207-12$

44 Crane JM, Armson BA, Dodds L, Feinberg RF, Kennedy W, Kirkland SA. Risk scoring, fetal fibronectin, and bacterial vaginosis to predict preterm delivery. Obstet Gynecol 1999;93:517-22.

45 Heath VC, Daskalakis G, Zagaliki A, Carvalho M, Nicolaides KH. Cervicovaginal fibronectin and cervical length at 23 weeks of gestation: relative risk of early preterm delivery. Br J Obstet Gynaecol 2000;107:127681 .

46 Coleman MA, McCowan LM, Pattison NS, Mitchell M. Fetal fibronectin detection in preterm labor: evaluation of a prototype bedside dipstick technique and cervical assessment. Am J Obstet Gynecol 1998;179:1553-8.

47 Coleman MA, Keelan JA, McCowan LM, Townend KM, Mitchell MD. Predicting preterm delivery: comparison of cervicovaginal interleukin (IL)-1beta, IL-6 and IL- 8 with fetal fibronectin and cervical dilatation. Eur J Obstet Gynecol Reprod Biol 2001;95:154-8.

48 Grandi C, Perego M, Briozzo G, Cassini A. Fibronectina fetal (fFN) en secrecion cervical como predictor del parto prematuro. Rev Hosp Mat In Ramon Sarda 1996:15:127-36.

49 Morrison JC, Allbert JR, McLaughlin BN, Whitworth NS, Roberts WE, Martin RW. Oncofetal fibronectin in patients with false labor as a predictor of preterm delivery. Am J Obstet Gynecol 1993;168:538-42.

50 Senden IPM, Owen P. Comparison of cervical assessment, fetal fibronectin and fetal breathing in the diagnosis of preterm labour. Clin Exp Obstet Gynecol 1996;23:5-9.

51 LaShay N, Gilson G, Joffe G, Qualls C, Curet L. Will cervicovagina interleukin-6 combined with fetal fibronectin testing improve the prediction of preterm delivery? J Matern Fetal Med 2000;9:336-41.

52 Luo L, Lu Q, Wei F. [Fetal fibronectin and preterm birth]. Zhonghua Fu Chan Ke Za Zhi 1997;32:25-6.

53 Gebhardt S, Odendaal HJ. Fetal fibronectin in vaginal secretions-a predictor of preterm delivery? [letter]. S Afr Med J 1995;85:188.

54 Hampl M, Friese K, Hofmann I, Melchert F. [Quantitative determination of fetal fibronectin in cervical smears: a new marker for evaluating the risk in premature labour.] Geburtshilfe Frauenheilkd 1994;54:685-90.

55 Khan KS, Chien PF. Seizure prophylaxis in hypertensive pregnancies: a framework for making clinical decisions. Br J Obstet Gynaecol 1997;104:1173-9

56 Usher RH, Allen AC, McLean FH. Risk of respiratory distress syndrome related to gestational age, route of delivery, and maternal diabetes. Am J Obstet Gynecol 1971:111:826-32.

57 Sinclair JC. Meta-analysis of randomized controlled trials of antenatal corticosteroid for the prevention of respiratory distress syndrome: discussion. Am J Obstet Gynecol 1995;173:335-44.

58 Giles W, Bisits A, Knox M, Madsen G, Smith R. The effect of fetal fibronectin testing on admissions to a tertiary maternal-fetal medicine unit and cost savings. Am J Obstet Gynecol 2000;182:439-42.

59 Lopez RL, Francis JA, Garite TJ, Dubyak JM. Fetal fibronectin detection as a predictor of preterm birth in actual clinical practice. Am J Obstet Gynecol 2000;182:1103-6.

60 Iams JD, Casal D, McGregor JA, Goodwin TM, Kreaden US, Lowensohn $\mathrm{R}$, et al. Fetal fibronectin improves the accuracy of diagnosis of preterm labor. Am J Obstet Gynecol 1995;173:141-5.

61 Leeson SC, Maresh MJA, Martindale EA, Mahmood T, Muotune A, Hawkes N, et al. Detection of fetal fibronectin as a predictor of preterm delivery in high risk asymptomatic pregnancies. Br J Obstet Gynaecol 1996;103:48-53.

62 Lukes AS, Thorp JM Jr, Eueker B, Pahel-Short L. Predictors of positivity for fetal fibronectin in patients with symptoms of preterm labor. $A m$ Obstet Gynecol 1997;176:639-41.

63 Malak TM, Sizmur F, Bell SC, Taylor DJ. Fetal fibronectin in cervicovaginal secretions as a predictor of preterm birth. $\mathrm{Br} J$ Obstet Gynaecol 1996;103:648-53.

64 McKenna DS, Chung K, Iams JD. Effect of digital cervical examination on the expression of fetal fibronectin. J Reprod Med 1999;44:796-800

65 Peaceman AM, Andrews WW, Thorp JM, Cliver SP, Lukes A, Iams JD, et al. Fetal fibronectin as a predictor of preterm birth in patients with symptoms: a multicenter trial. Am J Obstet Gynecol 1997;177:13-8.

66 Nageotte MP, Casal D, Senvei AE. Fetal fibronectin in patients at increased risk for premature birth. Am J Obstet Gynecol 1994;170:20-5.

67 Oliveira T, de Souza E, Mariani-Neto C, Camano L. Fetal fibronectin as a predictor of preterm delivery in twin gestations. Int J Gynecol Obste 1998;62:135-9.

68 Oliveira TA, Carvalho CM, de Souza E, Mariani-Neto C, Camano L. Detection of fetal fibronectin in twin pregnancies in relation to gestational age. Sao Paulo Med J 1999;117:121-4. 
69 Krems J, McGregor J, Hastings C, Hanson J. Fetal fibronectin in cervical secretions: an aid for predicting delivery in women at high risk for preterm delivery. Am J Obstet Gynecol 1995;172:406.

70 Nageotte MP, Hollenbach KA, Vanderwahl BA, Hutch KM. Oncofetal fibronectin in patients at increased risk for preterm delivery. Am J Obstet Gynecol 1992;166:274.

71 Garcia Alonso A, Ayala Mendez JA, Izquierdo Puente JC, Jimenez Solis G, Sanchez Martinez M. Presencia de fibronectina fetal en secrecion cervico-vaginal como predictor de parto pretermino [Presence of fetal fibronectin in cervico-vaginal secretion as predictor of premature labor]. Ginecol Obstet Mex 1999;67:23-8.

72 Greenhagen JB, Van Wagoner J, Dudley D, Hunter C, Mitchell M, Logsdon V, et al. Value of fetal fibronectin as a predictor of preterm delivery for a low-risk population. Am J Obstet Gynecol 1996;175:1054-6.

73 Zamora Scorza FC, Fernandez G, de Lamanna MP, Perez MC, Maris CA. Valor de la fibronectina fetal en secreciones cervicales en la prediccion del parto pretermino en pacientes con membranas integras. Rev Obstet Ginecol Venez 2000;60:15-22

74 Arinami Y, Hasegawa I, Takakuwa K, Tanaka K. Prediction of preterm delivery by combined use of simple clinical tests. J Matern Fetal Med 1999;8:70-3.

75 Goldenberg RL, Mercer BM, Meis PJ, Copper RL, Das A, McNellis D. The preterm prediction study: fetal fibronectin testing and spontaneous preterm birth. Obstet Gynecol 1996;87:643-8.

76 Goldenberg RL, Mercer BM, Iams JD, Moawad AH, Meis PJ, Das A, et al. The preterm prediction study: patterns of cervicovaginal fetal fibronectin as predictors of spontaneous preterm delivery. Am J Obstet Gynecol 1997;177:8-12.

77 Goldenberg RL, Klebanoff M, Carey JC, MacPherson C, Leveno KJ, Moawad AH, et al. Vaginal fetal fibronectin measurements from 8 to 22 weeks' gestation and subsequent spontaneous preterm birth. Am J Obstet Gynecol 2000;183:469-75.

78 Hux CH, Trolice MP, Kadar N. The value of a single fetal fibronectin assay as a screen for preterm labor and delivery. J Matern Fetal Med 1995; $4: 100-4$

79 Inglis SR, Jeremias J, Kuno K, Lescale K, Peeper Q, Chervenak FA, et al. Detection of tumor necrosis factor-alpha, interleukin-6, and fetal fibronectin in the lower genital tract during pregnancy: relation to outcome. Am J Obstet Gynecol 1994;171:5-10.

80 Lockwood CJ, Wein R, Lapinski R, Casal D, Berkowitz G, Alvarez M, et al. The presence of cervical and vaginal fetal fibronectin predicts preterm delivery in an inner-city obstetric population. Am J Obstet Gynecol 1993;169:798-804

81 Vercoustre L, Sotter S, Bouige D, Walch R. Place de la fibronectine foetale dans la prediction du travail. Resultats et commentatires a propos de 206 prelevements. [Fibronectin as a predictor of labor, results and discussion prelevements. [Fibronectin as a predictor of labor,
about 206 samples]. Gynecol Obstet 1996;4:23-32.

82 Malagrida L, Rozenberg P, Simon G, Giudicelli Y. Detection of fetal fibronectin in cervical and secretions to predict preterm birth. ImmunoAnal Biol Spec 1995; 10:355-9.

83 Surbek D, Bosiger H, Pavic N, Huber P, Almendral AC, Holzgreve W. [Fetal fibronectin as a predictor of preterm birth in patients at increased risk]. Z Geburtshilfe Neonatol 1997:201:15-20.

84 Roubille M, Mailliavin A, Biguet-Vernier B, Bon C, Golfier F, Pichot JC. Interet de la recherche de la fibronectine foetale dans le depitage du ris- que d'accouchement premature [Fetal fibronectin as predictor of preterm birth]. Ann Biol Clin Paris 1999;57:93-7.

85 Calda P, Cibula D, Doudova D, Binder T, Peterka T, Zizka Z, et al. Fetalni fibronektin v cerviko-vaginalnim sekretu--indikator pocinajiciho predcasneho porodu metodou membranove imunoeseje [Fetal fibronectin in cervico-vaginal secretions - an indicator of incipient premature labor using a membrane immunoassay]. Ceska Gynekol 1995;60:293-5.

86 Burrus DR, Ernest JM, Veille JC. Fetal fibronectin, interleukin-6, and C-reactive protein are useful in establishing prognostic subcategories of idiopathic preterm labor. Am J Obstet Gynecol 1995;173:1258-62.

87 Goffeng AR, Holst E, Milsom I, Lindstedt G, Lundberg PA, Andersch B. Fetal fibronectin and microorganisms in vaginal fluid of women with complicated pregnancies. Acta Obstet Gynecol Scand 1997;76:521-7.

88 Irion O, Matute J, Bischof P. [Prediction of prematurity with oncofoetal fibronectin. Prospective cohort study]. J Gynecol Obstet Biol Reprod Paris 1995;24:624-9.

89 Langer B, Boudier E, Schlaeder G. Cervico-vaginal fetal fibronectin: predictive value during false labor. Acta Obstet Gynecol Scand 1997;76:218-21.

90 Parker J, Bell R, Brennecke S. Fetal fibronectin in the cervicovaginal fluid of women with threatened preterm labour as a predictor of delivery before 34 weeks' gestation. Aust N ZJ Obstet Gynaecol 1995;35:257-61.

91 Rizzo G, Capponi A, Arduini D, Lorido C, Romanini C. The value of fetal fibronectin in cervical and vaginal secretions and of ultrasonographic examination of the uterine cervix in predicting premature delivery for patients with preterm labor and intact membranes. Am J Obstet Gynecol 1996; 175:1146-51.

92 Rizzo G, Capponi A, Vlachopoulou A, Angelini E, Grassi C, Romanini C. The diagnostic value of interleukin- 8 and fetal fibronectin concentrations in cervical secretions in patients with preterm labor and intact membranes. J Perinat Med 1997;25:461-8.

93 Rozenberg P, Goffinet F, Malagrida L, Giudicelli Y, Perdu M, Houssin I, et al. Evaluating the risk of preterm delivery: a comparison of fetal fibronectin and transvaginal ultrasonographic measurement of cervical length. Am J Obstet Gynecol 1997;176:196-9.

94 Wennerholm UB, Holm B, Mattsby-Baltzer I, Nielsen T, Platz-Christensen J, Sundell G, et al. Fetal fibronectin, endotoxin, bacterial vaginosis and cervical length as predictors of preterm birth and neonatal morbidity in twin pregnancies. Br J Obstet Gynaecol 1997;104:1398-404.

95 Chuileannain FN, Bell R, Brennecke S. Cervicovaginal fetal fibronectin testing in threatened preterm labour-translating research findings into clinical practice. Aust N ZJ Obstet Gynaecol 1998;38:399-402.

96 Vetr M, Kudela M, Prasilova J. Fetal fibronectin in patients at increased risk for premature birth. Acta Univ Palacki Olomuc Fac Med 1996;140:55-7.

97 Cox S, Little B, Dax J, Leveno K. Fetal fibronectin and preterm delivery Am J Obstet Gynecol 1996;174:306.

98 Mansouri A, Tadjerouni A, El Rabiey G, Baube S, Garnier G, Tribalat S. [Is fetal fibronectin a valid test predictive of preterm delivery?]. Contracept Fertil Sex 1997;25:380-4.

99 Patricot MC, Pallant DA, Mathian B. Fetal fibronectin for prediction of preterm delivery. ImmunoAnal Biol Spec 1997;12:81-4.

(Accepted 13 March 2002) 